\title{
Mobile phone use while driving: Underestimation of a global threat
}

\section{Abstract}

The use of mobile phone (cell phone) has increased dramatically in the $21^{\text {st }}$ century. The popularity of mobile phones and smart phones in the computer age can in part be associated with the growing problem of driver distraction. There are indications that the use of mobile phones while driving is one of the leading contributors to road traffic collisions (RTCS). However the true impact of the contribution of mobile phones to RTCs is masked by deficiencies in reporting. This review examines the evidence of association between mobile phone use and RTCs, placing emphasis on the challenges associated with reporting the role of mobile phone in RTCs across different countries including the United States of America, Canada, China and Great Britain.

\section{Introduction}

Over the past decades, there has been an increasing problem of driver distraction (Engelberg et al., 2015). Although, the term 'distracted driving' (DD) is subject to several interpretations, NHTSA describes DD as any activity that could divert a person's attention away from the primary task of driving to other activities (NHTSA, 2015c). Diversion of a driver's attention could either be from sources internal or external to the vehicle. Internal sources include the use of mobile phones while driving, eating while driving, talking to passengers, smoking, reading (books, texts), using a navigation system, watching television and movies via tablet devices, adjusting a radio, CD player, or MP3 player among others (NHTSA, 2010; Strayer and Drews, 2004). Those external to the vehicle include looking at moving objects outside the vehicle or watching people on the side of the road (NHTSA, 2010). Distraction can take several forms including physical (taking hands off the steering wheel), visual (taking eyes off the road), cognitive (taking minds off the road) and auditory (Olson et al., 2009; WHO, 2011). The impact of driver distraction varies according to the source of distraction, form, frequency and duration of distraction. WHO (2011) suggests that the risk of an RTC increases with the frequency and length of distraction. The consequences of RTCs resulting from driver distraction is devastating, in terms of both 
deaths and injuries (Farmer et al., 2010; Hoff et al., 2013; NHTSA, 2015b; Vegega et al., 2013).

\section{Evidence of an association between mobile phone use while driving and Road Traffic Collisions}

The use of mobile phones while driving is one of the most serious forms of distraction. This might be largely due to the fact that mobile phone use while driving requires visual, physical and cognitive attention of the driver (Caird et al., 2008; Horrey et al., 2006; McCartt et al., 2006; Olson et al., 2009; Strayer et al., 2006). Brookhuis et al. (1991) contended that mobile phone use (for calling and texting) whilst driving significantly decreases drivers' vehicle control ability resulting in a. four-fold increase in the risk of RTCs (Redelmeier and Tibshirani, 1998). Similarly, the World Health Organisation estimates that drivers who use mobile phones for text messaging or calling while driving have between a $2 \%$ and $9 \%$ increased risk of an RTC (WHO, 2011). The argument of the comparative safety of handsfree has also been dispelled by Strayer and Drews (2004) who revealed that using handsfree devices impairs driving performance in both young and experienced drivers.

Epidemiological studies suggest that mobile phone use (handheld or hands-free) increases a driver's crash risk by a factor of four (Redelmeier and Tibshirani, 1997; McEvoy et al., 2005). An earlier epidemiological case-control study in the USA found that talking for more than 50 min per month on a mobile phone was associated with a 5.59-fold increased risk of road traffic accident (Violanti and Marshall, 1996). There are also indications that text messaging might be more dangerous than making or receiving a phone call while driving (Yannis et al., 2014). This is because in addition to cognitive impairment, sending a text message while driving also keeps the driver's eyes away from the road (physical impairment) for at least five seconds and one or both hands from the wheel. This equals the time taken to cover the entire length of a football field blindfolded when driving at $55 \mathrm{mph}$ (Olson et al., 2009). Additionally, a simulator study by Drews et al. (2009) revealed that texting while driving increases the risk of an RTC by six fold. Similarly, Olson et al., (2009) argued that the probability of an RTC increases by 23.3 and 5.9 times among drivers who text and call respectively. This seems to support the findings from Klauer et al. (2006) which indicates 
that a driver is 3.38 times more likely to be in a crash or near-crash while reading and driving than if she/he were just driving normally (Klauer et al., 2006).

The burden of RTC associated with distracted driving appears to higher among young drivers aged 15 to 19 (Hosking et al., 2009; NHTSA, 2015a; Tison et al., 2011; WHO, 2011). Frequent use of mobile phones (for browsing, calling or texting) while driving, and the lack of driving experience are plausible explanations for this trend (Hosking et al., 2009; Klauer et al, 2006; WHO, 2011). Although teenage drivers are at a higher risk of a mobile phone related RTC, this does not suggests that older adults and experienced drivers are exempted from the consequences of using mobile phones while driving (WHO, 2011).

The impact of the contribution of mobile phones to RTCs is masked by under-recording and under-reporting. In many countries, police reported data represent the sole or major source of information on the association between mobile phone use and RTCs (National Safety Council, 2012). Other government organisations and non-government organisations including insurance companies and employers also play a role in monitoring and controlling mobile phone use while driving (WHO, 2011). However, there are several issues affecting the validity of reported data; one of such is the problem of under-reporting. This review examines the manner of reporting the contribution of mobile phone use to RTCs across different countries. The review further identifies the risk factors associated with underreporting and offers some possible solutions.

\section{Recording and reporting of mobile phone involvement in RTCS}

In a bid to reduce the prevalence of distracted driving and mortality associated with it, several laws have been implemented in a number of countries to restrict the use of mobile phones while driving (U.S Department of Transportation National Highway Traffic Safety Administration, 2010; WHO, 2011). However, there is a paucity of evidence on the effectiveness of such measures. This is partly linked with the unavailability of comprehensive and complete data on the role of mobile phones in RTCs (Beck et al., 2007; WHO, 2011). 
Police officers are often charged with the responsibility of providing information on RTCS within their jurisdictions. The quality of the data captured is sometimes measured by its completeness and ability to provide contextual information on risk factors underlying each investigated crash (Loo and Tsu, 2007). However, evidence suggests that police reports do not provide reliable information to assess the risk factors surrounding a collision (Ma et al., 2012; Wilson, Fang and Wiggins, 2003), particularly on the involvement of mobile phones (WHO, 2011). This makes it difficult to assess whether a causal relationship exists between mobile phone use and crash involvement. The subject of under-reporting of involvement of mobile phones and other risk factors in RTCs has a long history. A study conducted by Harris et al. (1990) in the Netherlands revealed that police recording of RTCs and risk factors are un-representative and incomplete. Under-reporting is a broad term that encompasses both deficiencies in reporting and recording (Thomas and Astrop, 2000). For the purpose of this review, the term 'under-reporting' will be used.

Several measures such as surveys and in-video footage of vehicles are being adopted to estimate the true prevalence of distracted driving in different countries including the United States (NHTSA, 2010), New Zealand (Sullman and Baas, 2004), and Canada (WHO, 2011) . A major drawback however, is that these methods often utilise self-reported data from drivers and hence rely on driver sincerity (Asbridge et al., 2012). The difficulty in capturing mobile phone involvement increases if a collision occurs. This might be as a result of the challenges associated with in encouraging drivers to admit to mobile phone use, since it is an offence (National Safety Council, 2012) and the interest of the police in recording more obvious violations such as speeding (Asbridge et al., 2012). Ma et al. (2012) noted that police officers are more interested in identifying evidence that can be used for prosecution and since mobile phone use at the exact moment of collision is often considered as a subjective judgement of the police, it is not given due attention.

\section{Country Specific under-reporting}

\section{Case Study: United States}

In the United States, data on traffic fatalities are recorded on the National Highway Traffic Safety Administration (NHTSA) Fatality Analysis Reporting System (FARS). FARS is a 
nationwide statistics database that provides annual data on fatal motor vehicle injuries and risk factors. Different agencies are involved in data collection and compilation, including local groups within communities and state agencies. The National Safety Council (2012) indicated that although the FARS data provides valuable information that can be used to advocate for policy change, it suffers from under-reporting of important risk factors such as the involvement of mobile phone in fatal car collisions. NHTSA admitted that risk factors for distraction are often under-reported in the FARS data and it could take several years for substantial improvements to be made (NHTSA 2015a; NHTSA 2015b). This is primarily due to the reliance on self-reported data from drivers and the focus of law enforcement officers on reporting violations for legal prosecution (National Highway Traffic Safety Administration, 2010; U.S. Department of Transportation). Another key challenge in the United States is the inconsistency in the method of reporting by law enforcement officers. There is no standardised reporting format across all states. In some states, such as Oklahoma and Tennessee, the report form contains a specific field to account for distraction, while other jurisdictions rely on narrative summaries of police reports to identify elements of driver distractions (Lissy et al., 2000; U.S. Department of Transportation, National Highway Traffic Safety Administration, 2013). This appears to be similar to the manner of reporting in Australia and Sweden (U.S. Department of Transportation, National Highway Traffic Safety Administration, 2010). However, it has now become a requirement in the USA for law enforcement officers to collect information on involvement of mobile phone in an RTC (WHO, 2011). It is recommended that governments in other countries should proactively seek measures to improve and modify existing collision reports, in a bid to provide an unbiased estimate of the role of mobile phones in RTC (WHO, 2011).

\section{Case Study: China}

Ma et al., (2012) indicated that the burden of road traffic fatalities in China is estimated by four national level surveillance systems; Ministry of Health Vital Registration System; Chinese CDC Surveillance Points (DSP); Chinese CDC National Injury Surveillance System (NISS) and police reported data. The researchers argued that police reported data is the only Chinese surveillance system that provides some information on the contextual factors surrounding a crash. Unlike the United States, the Chinese police have a standardised close ended data collection form that lists over 20 risk factors for each crash. Police officers assign 
one risk factor as the most direct cause of the crash (Hu et al., 2011). The consequence of this method of reporting is that there is often an underestimation of risk factors such as involvement of mobile phones. For instance in a situation where a crash occurs as a result of driver distraction where the driver takes a wrong turn, the police are more likely to assign the code 'wrong direction' as the cause of the crash despite the fact that the underlying cause of the crash might have been driver distraction (Ma et al., 2012). Hu, Baker and Barker (2010) recommended that efforts should be directed at auditing and monitoring the quality of police-reported data with a view to improving data quality.

\section{Case Study: Canada}

In Canada, data on RTCs is obtained from the Traffic Accident System (TAS). TAS data is compiled by reconciling data from police reports and coroners' data (Asbridge et al., 2012). A report from British Columbia suggests that the problem of under-reporting might relate to deficiencies in recording risk factors and not attending all reportable collisions. Regarding under-recording of risk factors, the report indicates that the police officers are more likely to record dangerous manoeuvres and violation of traffic rules as the cause of the crash, even if mobile phone distraction was primarily involved in the collision (British Columbia, 2005). A report from the Canadian Council of Motor Transport Administrators (2010) indicates that efforts are underway to implement changes in the method of police reporting of crashes and improve the consistency of data collection across the country.

\section{Case Study: Great Britain}

In Great Britain, investigations of risk factors of road traffic collisions are performed using three main sources of information: In-depth investigations involving co-operation of police forces and hospitals, the national 'STATS19' database of all injury RTCs (Pilkington et al., 2014) and police fatal accident reports (Harris et al., 1990). Although the STATS19 database has the potential for providing intelligence for estimating the prevalence of risk factors associated with RTCs, Pilkington et al., (2014) and Durbin et al., (2015) argued that there are important gaps in collecting detailed contextual information and risk factors on RTCs.

In 2011, it was estimated that distraction contributes to around $2 \%$ of reported crashes in Great Britain (WHO, 2011). However a study of in-vehicle video footage of driver behaviour estimated that about $22 \%$ of crashes could be associated (in part) with driver distraction 
(National Highway Traffic Safety Administration, 2006). Although the later study was conducted in the US, the difference between both countries appears to reflect the issue of under-reporting. One of the plausible factors for under-reporting in the UK relates to the perceived lack of authority of police officers to seize mobile phones from drivers (Horsman and Connis, 2015). In most cases, except in the event of a fatality, police officers are not allowed to seize and inspect mobile phones of drivers (Horsman and Connis, 2015). Thus, police officers and road traffic officers are largely incapacitated in their ability to obtain evidence from drivers.

\section{Conclusions and recommendations}

The inconsistency in police recording and reporting of mobile phone use while driving has been well documented in Great Britain and other developed countries. It is striking that, while legislation to ban mobile phone use while driving has been implemented in a number of countries worldwide, there is inadequate evidence to evaluate the effectiveness of such legislation due to challenges of under-reporting. The study by Amoros et al., (2006) indicates that the problem of under-reporting is a world-wide phenomenon and should be addressed by a global strategy to improve data collection. Jacobs et al. (2000) recommended that police should be assisted to improve their crash recording systems. Similarly, the WHO emphasised the need to support police officers and law enforcement officers to improve data collection of risk factors of RTCs (WHO, 2011). Thus, the need for a more complete, fitfor-purpose data collection system to account for RTCs attributable to the use of mobile phones and other sources of distraction cannot be over-emphasized. The true scope of distracted driving and the burden of injuries from mobile phone use while driving can only be estimated through comprehensive recording and reporting of such risk factors.

The issue of under-reporting of the contribution of mobile phones to RTCs necessitates the need to design a more effective means of detecting and analysing mobile phone usage at the scene of a crash. Firstly, there is need to make provisions for authorised road traffic investigators to be able to seize mobile phones for analysis at the scene of a crash. This is because police officers in some countries including the United Kingdom do not have the legal backing to obtain mobile phones from drivers suspected to have been involved in a 
non-fatal crash involving mobile phone use. In addition, there is also an argument for timely analysis of data once mobile phones have been retrieved. Most RTC forms are completed at the scene of the crash. The time lag between completion of the crash report and analysis of the phone to establish evidence might increase the odds of under-reporting. Consequently, police officers and road traffic investigators should be adequately trained on how to carry out timely analysis of mobile phones. This view is supported by Hosman and Connis (2015) who indicated that investigation officers should be adequately trained on how to use available technological options such as analysis of iPhone's CurrentPowerlog.powerlog and Android's buffer logs to identify evidence for mobile phone use. Another technological option that can assist with gathering evidence of mobile phone involvement in RTCs is the installation of in-vehicle cameras. This approach serves a number of purposes: providing useful information to determine the risk factor(s) responsible for a crash; assisting with prosecutions by providing evidence of driver actions at the time of an RTC; and also deterring drivers from engaging in any risky behaviour while driving. However, this technique relies heavily on a driver's acceptance and willingness to purchase the device. Insurance companies can be potentially valuable in promoting the use of these technological devices, through the offer of reduced premiums to adopters.

Moreover, there is need to improve the system for data collection at the scene of an RTC. Evidence from this review suggests that in most cases, collision report forms are neither flexible nor detailed enough to record several probable crash risk factors. Future research should be directed towards improving data collection regarding the contribution of mobile phones to RTCs and how to deter drivers from using their phones whilst driving. 


\section{REFERENCES}

Amoros, E., Martin, J. and Laumon, B. (2006). Under-reporting of road crash casualties in France. Accident Analysis \& Prevention, 38 (4), 627-635.

Asbridge, M., Brubacher, J.R. and Chan, H. (2013). Cell phone use and traffic crash risk: A culpability analysis. International Journal of Epidemiology, 42 (1), 259-267.

Bayer, J. B., and Campbell, S. W. (2012). Texting while driving on automatic: Considering the frequency-independent side of habit. Computers in Human Behavior, 28(6), 2083-2090.

Beck, K. H., Yan, F., and Wang, M. Q. (2007). Cell phone users, reported crash risk, unsafe driving behaviors and dispositions: A survey of motorists in Maryland. Journal of safety research, 38(6), 683-688.

British Columbia. (2005). Traffic Collision Statistics: Police-attended Injury and Fatal Collisions. Available

at: http://s3.amazonaws.com/zanran_storage/www.llbc.leg.bc.ca/ContentPages/528027285.p df. Accessed on the 28th May, 2015.

Brookhuis, K. A., de Vries, G., and de Waard, D. (1991). The effects of mobile telephoning on driving performance. Accident Analysis \& Prevention, 23(4), 309-316.

Caird, J.K., Willness, C.R., Steel, P. and Scialfa, C. (2008) A meta-analysis of the effects of cell phones on driver performance. Accident Analysis \& Prevention [online]. 40 (4), pp.12821293.

Canadian Council of Motor Transport Administrators. (2010). Stride Expert Working Group on Distraction. Available at: http://www.bv.transports.gouv.qc.ca/mono/1061277.pdf. Accessed on 29 May 2015

Department of Transport. (2005). Development and Implementation of the UK on the Spot Accident Data Collection Study - Phase I. Available at: http://www.lboro.ac.uk/media/wwwlboroacuk/content/lds/downloads/research/researchg roups/tsrc/dft-rsrr59-ots-phase1.pdf. Accessed on the 31st May, 2015.

Department of Transport. (2009) Reported road casualties Great Britain 2008 - Annual Report. 
http://www.dft.gov.uk/pgr/statistics/datatablespublications/accidents/casualtiesgbar/rrcgb 2008 Accessed on 29 May 2015

Drews, F.A., Yazdani, H., Godfrey, C.N., Cooper, J.M. and Strayer, D.L. (2009) Text messaging during simulated driving. Human Factors. 51 (5), pp.762-770.

Durbin, D.R., Myers, R.K., Curry, A.E., Zonfrillo, M.R. and Arbogast, K.B. (2015). Extending the value of police crash reports for traffic safety research: collecting supplemental data via surveys of drivers. Injury Prevention: Journal of the International Society for Child and Adolescent Injury Prevention, 21, e36-e42.

Engelberg, J. K., Hill, L. L., Rybar, J., and Styer, T. (2015). Distracted driving behaviors related to cell phone use among middle-aged adults. Journal of Transport \& Health, 2(3), 434-440.

Farmer, C.M., Braitman, K.A. and Lund, A.K. (2010) Cell Phone Use While Driving and Attributable Crash Risk. Traffic Injury Prevention. 11 (5), pp.466-470.

Harris, S. (1990). The real number of road traffic accident casualties in The Netherlands: A year-long survey. Accident, Analysis and Prevention, 22 (4), 371-378.

Hoff, J., Grell, J., Lohrman, N., Stehly, C., Stoltzfus, J., Wainwright, G. and Hoff, W.S. (2013) Distracted driving and implications for injury prevention in adults. Journal of Trauma Nursing: The Official Journal of the Society of Trauma Nurses. 20 (1), pp.31-4; quiz 35-6.

Horrey, W.J. and Wickens, C.D. (2006) Examining the impact of cell phone conversations on driving using meta-analytic techniques. Human Factors. 48 (1), pp.196-205.

Horsman, G., \& Conniss, L. R. (2015). Investigating evidence of mobile phone usage by drivers in road traffic accidents. Digital Investigation, 12, S30-S37.

Hosking, S.G., Young, K.L. and Regan, M.A. (2009) The Effects of Text Messaging on Young Drivers. Human Factors: The Journal of the Human Factors and Ergonomics Society . 51 (4), pp.582-592. 
Hu, G., Baker, T. and Baker, S.P. (2011). Comparing road traffic mortality rates from policereported data and death registration data in China. Bulletin of the World Health Organization, 89 (1), 41-45. Available from: http://www.who.int/bulletin/volumes/89/1/10080317/en/ Assessed on 03 June 2015

Jacobs, G., Aeron-Thomas, A. and Astrop, A. (2000). Estimating Global Road Fatalities. Available from http://www.transportlinks.org/transport_links/filearea/publications/1_329_trl445.pdf Assessed on 20 September 2015.

Karen S. Lissy, Joshua T. Cohen, Mary Y. Park, M.S. John D. Graham. (2000). Cellular phone use while driving. Harvard Center for Risk Analysis, Harvard School of Public Health Boston, Massachusetts Available at:_http://www.nsc.org/DistractedDrivingDocuments/CellularPhone-Use-While-Driving-Risk-and-Benefits.pdf. Accessed on 26 May 2015

Klauer, S.G., Dingus, T.A., Neale, V.L., Sudweeks, J. and Ramsey, (2006) The Impact of Driver Inattention on Near-Crash/Crash Risk: An Analysis using the 100-Car Naturalistic Driving Study Data. Report number: DOT HS 810594.

Ma, S., Li, Q., Zhou, M., Duan, L. and Bishai, D. (2012). Road traffic injury in China: A review of national data sources. Traffic Injury Prevention, 13 (1), 57-63.

McCartt, A.T., Hellinga, L.A. and Bratiman, K.A. (2006) Cell phones and driving: review of research. Traffic Injury Prevention .7 (2), pp.89-106.

McEvoy, S.P., Stevenson, M.R., McCartt, A.T., Woodward, M., Haworth, C., Palamara, P. and Cercarelli, R. (2005) Role of mobile phones in motor vehicle crashes resulting in hospital attendance: a case-crossover study. BMJ [online]. 331 (7514), pp.428.

National Highway Traffic Safety Administration. (2006). The impact of driver inattention on near-crash/crash risk: An analysis using the 100-car naturalistic driving study data. Available from: http://www-nrd.nhtsa.dot.gov/pdf/esv/esv19/05-0400-W.pdf. Accessed on 22 May 2015 
National Highway Traffic Safety Administration. (2010). Overview of Results From the International Traffic Safety Data and Analysis Group Survey on Distracted Driving Data $\begin{array}{llll}\text { Collection and } & \text { Reporting. Available }\end{array}$ http://www.distraction.gov/downloads/pdfs/traffic-saftey-facts-crash-stats-10-2010.pdf. Accessed on 24 May 2015

National Highway Traffic Safety Administration. (2010). Overview of the National Highway $\begin{array}{llll}\text { Traffic } & \text { Safety } & \text { Administration's. }\end{array}$ https://www.google.co.uk/url?sa=t\&rct=j\&q=\&esrc=s\&source=web\&cd=1\&cad=rja\&uact=8 \&ved=0CCEQFjAAahUKEwjm9z58sTIAhXJVRQKHcQyBV8\&url=http\%3A\%2F\%2Fwww.nhtsa.gov\%2Fstaticfiles\%2Fnti\%2Fdist racted_driving\%2Fpdf\%2F811299.pdf\&usg=AFQjCNHtO1j9n_no7qp0ilmYBME0ylBonw\&sig2 =T11QuMIJOFEm7mJNBPb9cg Accessed on 15 October 2015

National Safety Council. (2012). Crashes Involving Cell Phones; Challenges of Collecting and Reporting Reliable Crash Data. Available from: http://www.nsc.org/DistractedDrivingDocuments/NSC-Under-Reporting-White-Paper.pdf. Accessed on 19 May 2015

NHTSA (2015a) Distracted Driving 2013. Traffic Safety Facts Research Note. Available from: http://www.distraction.gov/downloads/pdfs/Distracted_Driving_2013_Research_note.pdf .

NHTSA, (2015b) Distracted Driving 2013. Traffic Safety Facts Research Note. Report number: DOT HS 812 132.Washington, DC: National Highway Traffic Safety Administration.

NHTSA (2015c) What is Distracted Driving? Facts and Statistics. Available from: http://www.distraction.gov/stats-research-laws/facts-and-statistics.html .

Pilkington, P., Bird, E., Gray, S., Towner, E., Weld, S. and McKibben, M.A. (2014). Understanding the social context of fatal road traffic collisions among young people: A qualitative analysis of narrative text in coroners' records. BMC Public Health, 14, 78-245814-78. 
Ranney, T. A., Mazzae, E., Garrott, R., and Goodman, M. J. (2000, July). NHTSA driver distraction research: Past, present, and future. In Driver Distraction Internet Forum (Vol. 2000).

Redelmeier, D.A. and Tibshirani, R.J. (1997). Association between Cellular-Telephone Calls and Motor Vehicle Collisions. The New England Journal of Medicine, 336 (7), 453-458.

Salifu, M. and Ackaah, W. (2012). Under-reporting of road traffic crash data in Ghana. International Journal of Injury Control and Safety Promotion, 19 (4), 331-339.

Strayer, D. L., and Drew, F. A. (2004). Profiles in driver distraction: Effects of cell phone conversations on younger and older drivers. Human Factors: The Journal of the Human Factors and Ergonomics Society, 46(4), 640-649.

Sullman, M. J., \& Baas, P. H. (2004). Mobile phone use amongst New Zealand drivers. Transportation Research Part F: Traffic Psychology and Behaviour, 7(2), 95-105.

U.S Department of Transportation, National Highway Traffic Safety Administration. (2013). Traffic Safety Facts Research Note. Distracted Driving 2013. Available at: http://www.distraction.gov/downloads/pdfs/Distracted_Driving_2013_Research_note.pdf. Accessed on 23 May 2015

WHO. (2011). Mobile Phone Use: A growing Problem of Driver Distraction. Available at: http://www.who.int/violence_injury_prevention/publications/road_traffic/distracted_drivi ng_en.pdf. Accessed on 19 May 2015

Wilson, J., Fang, M., Wiggins, S. and Cooper, P. (2003). Collision and violation involvement of drivers who use cellular telephones. Traffic Injury Prevention, 4(1), 45-52.

Young, K., Regan, M., and Hammer, M. (2007). Driver distraction: A review of the literature. Distracted driving, 379-405. 